University of Nebraska - Lincoln

DigitalCommons@University of Nebraska - Lincoln

SENSITIVITY OF FISH EMBRYOS TO WEATHERED CRUDE OIL:

PART II. INCREASED MORTALITY OF PINK SALMON (ONCORHYNCHUS GORBUSCHA) EMBRYOS INCUBATING DOWNSTREAM FROM WEATHERED EXXON VALDEZ CRUDE OIL

\author{
Ron A. Heintz \\ ron.heintz@noaa.gov \\ Jeffrey W. Short \\ NOAA \\ Stanley D. Rice \\ NOAA
}

Follow this and additional works at: https://digitalcommons.unl.edu/usdeptcommercepub

Part of the Environmental Sciences Commons

\begin{abstract}
Heintz, Ron A.; Short, Jeffrey W.; and Rice, Stanley D., "SENSITIVITY OF FISH EMBRYOS TO WEATHERED CRUDE OIL: PART II. INCREASED MORTALITY OF PINK SALMON (ONCORHYNCHUS GORBUSCHA) EMBRYOS INCUBATING DOWNSTREAM FROM WEATHERED EXXON VALDEZ CRUDE OIL" (1999). Publications, Agencies and Staff of the U.S. Department of Commerce. 277.

https://digitalcommons.unl.edu/usdeptcommercepub/277
\end{abstract}

This Article is brought to you for free and open access by the U.S. Department of Commerce at DigitalCommons@University of Nebraska - Lincoln. It has been accepted for inclusion in Publications, Agencies and Staff of the U.S. Department of Commerce by an authorized administrator of DigitalCommons@University of Nebraska - Lincoln. 


\title{
SENSITIVITY OF FISH EMBRYOS TO WEATHERED CRUDE OIL: PART II. INCREASED MORTALITY OF PINK SALMON (ONCORHYNCHUS GORBUSCHA) EMBRYOS INCUBATING DOWNSTREAM FROM WEATHERED EXXON VALDEZ CRUDE OIL
}

\author{
Ron A. Heintz, * Jeffrey W. Short, and Stanley D. Rice \\ National Marine Fisheries Service, NOAA, Alaska Fisheries Science Center, Auke Bay Laboratory, 11305 Glacier Highway, \\ Juneau, Alaska 99801-8626, USA
}

(Received 29 October 1997; Accepted 15 June 1998)

\begin{abstract}
We incubated pink salmon embryos under three exposure conditions, direct contact with oil-coated gravel, effluent from oil-coated gravel, and direct contact with gravel coated with very weathered oil (VWO). Embryo mortalities and polynuclear aromatic hydrocarbon (PAH) accumulation in embryo tissues during the direct-contact and effluent exposure experiments were not significantly different, indicating that PAH accumulation was mediated by aqueous transport. Mortality rates for embryos exposed initially to a total PAH concentration (TPAH) of $1.0 \mathrm{ppb}$ were significantly higher than controls when the PAH were derived from VWO. The same aqueous TPAH concentration failed to increase mortality rates when the PAH were derived from less weathered oil, indicating that toxicity of effluents from the VWO was primarily associated with the larger PAH. We conclude that water quality standards for TPAH above $1.0 \mathrm{ppb}$ may fail to protect fish embryos. Further, pink salmon embryos incubating in Prince William Sound after the Exxon Valdez oil spill may have accumulated lethal concentrations of PAH from interstitial water that was contaminated when it percolated through oil reservoirs located upstream from salmon redds.
\end{abstract}

Keywords-Toxicity Pink salmon Exon Valdez Polynuclear aromatic hydrocarbons Oil spill

\section{INTRODUCTION}

The reported effects of the Exxon Valdez oil spill of March 1989 on pink salmon (Oncorhynchus gorbuscha) incubating in Prince William Sound (PWS), Alaska, remain controversial. After the spill, Bue et al. [1] compared embryo mortality rates of streams traversing oiled and unoiled beaches. They concluded that between 1989 and 1993 pink salmon eggs deposited in the intertidal sections of oiled-beach streams had higher mortality rates than eggs in similar sections of streams on unoiled beaches. They later reported no differences in mortality rates between streams on oiled and unoiled beaches in 1994 and 1995, suggesting a temporal pattern of declining mortality consistent with decreasing oil abundance on oiled beaches [2]. However, a comparable study reported no differences in mortality rates between streams on oiled and unoiled beaches [3] in 1989, even though both studies surveyed many of the same streams. Based on low concentrations of polynuclear aromatic hydrocarbons (PAHs) measured on stream bed gravels, Brannon et al. [3] concluded pink salmon embryos in streams on oiled beaches received little exposure to PAHs.

The study by Brannon et al. [3] did not consider the possibility that pink salmon embryos may have accumulated waterborne PAHs from upstream intertidal sources. In the intertidal of PWS, spilled Exxon Valdez oil (EVO) persisted mainly in the higher tidal reaches of beaches adjacent to and usually upstream of spawning habitat used by pink salmon [4]. Oil

* To whom correspondence should be addressed (ron.heintz@noaa.gov).

The research described in this paper was supported by the Exxon Valdez Oil Spill Trustee Council. However, the findings and conclusions presented by the authors are their own and do not necessarily reflect the view or position of the Trustee Council. was usually excluded from freshwater stream channels that traverse this intertidal habitat [3] and to which pink salmon return to spawn. However, tidal action could force interstitial water past oil-contaminated gravel toward intertidal salmon redds, and pink salmon embryos could absorb PAHs from the transported water. Developing pink salmon in PWS reside in spawning gravels for up to $200 \mathrm{~d}$ and are $60 \%$ lipid for the first $100 \mathrm{~d}$ [5]. Thus, they may act as lipid packets accumulating PAH from sporadic, low-level exposure. Measurement of PAH concentrations in developing pink salmon embryos collected from redds of streams on oiled beaches would have been a more sensitive indication of exposure, but unfortunately such measurements were not reported by either Bue et al. [1] or by Brannon et al. [3].

We conducted a laboratory study of damage to pink salmon embryos caused by prolonged exposure to low concentrations of PAHs dissolved from EVO to evaluate whether the mortalities reported by Bue et al. [1] could have resulted from accumulation of PAHs leached from EVO stranded in PWS. Impaired development of emergent pink salmon fry has been reported following prolonged exposure to total PAH concentrations that declined from 4.4 parts per billion (ppb) [6], which suggests possible mortality at earlier developmental stages. Here, we report results of laboratory studies postulated to simulate the PAH exposure conditions for pink salmon embryos in streams on oiled beaches of PWS. Our objectives are to determine the concentration of total PAH leached from oilcontaminated gravel that increases mortality of pink salmon embryos, whether direct contact with oiled gravel is necessary for pink salmon embryos to accumulate lethal concentrations of PAHs, and the persistence of oil toxicity associated with very weathered oil (VWO). This last objective is necessary to 
evaluate whether the toxic components of oil may be sufficiently persistent in the environment to account for toxic effects 4 years following the spill as reported by Bue et al. [1].

\section{METHODS}

\section{Experimental overview}

The primary experiment, called the direct-exposure experiment, simulated salmon redd conditions where pink salmon embryos were reared in direct contact with oil-contaminated gravel. We also performed two subsidiary experiments. One, called the indirect-exposure experiment, was similar to the direct-exposure experiment, except that embryos did not directly contact oil-contaminated gravel and were exposed only to water-contaminated by PAHs leached from oil-contaminated gravel. Another, called the weathered-oil experiment, was also similar to the direct-exposure experiment except that the oilcontaminated gravel used was weathered for 1 year prior to use. We further evaluated how compositional differences in oil affect toxicity by comparing PAH uptake rates in embryos from the direct-exposure experiment with embryos from the weathered-oil experiment with a simple first-order kinetic model. Apart from the differences described, the apparatus, fish-culture methods, and hydrocarbon analysis methods were common to all three experiments.

We concurrently monitored PAH concentrations on the oilcontaminated gravels, in water that eluted from oiled gravels, and in the exposed embryos during all three experiments. We refer to these respective measurements as gravel-, aqueous-, and tissue-PAH concentrations. Gravel- and tissue-PAH concentrations are expressed in parts per million (ppm or micrograms per gram) and aqueous-PAH concentrations as pbb (or micrograms per liter). We also use the term "oil dose" to refer to the concentration of whole oil on gravel, expressed as ppm present at the beginning of the experiments.

\section{Direct-exposure experiment}

We incubated pink salmon eggs in incubators that contained gravel contaminated with one of seven doses, of which one was a control dose of uncontaminated gravel. Each dose was replicated in 8 incubators, except for the highest oil dose, which was replicated in 15 to ensure adequate numbers of survivors for a separate study. The exposure apparatus, fertilization, fish culture, and hydrocarbon sampling procedures followed Marty et al. [6] and are summarized as follows.

Oil exposure apparatus. We exposed eggs to oil in incubators constructed of $60 \mathrm{~cm}$ tall polyvinyl chloride tubes (15$\mathrm{cm}$ diameter) stood on end, filled with contaminated gravel, and supplied with water that percolated upward. Gravel was contaminated by spraying measured quantities of artificially weathered Alaska North Slope crude oil on tumbling gravel. The oil was artificially weathered by heating it to $70^{\circ} \mathrm{C}$ until its initial mass was reduced by approximately $20 \%$. The resulting composition simulated that of the oil stranded on PWS beaches in 1989 where napthalenes represented approximately $80 \%$ of the TPAH [7]. On September 11, 1993, approximately $10.7 \mathrm{~kg}$ of gravel was loaded into each incubator, and water was introduced at a rate of $150 \mathrm{ml} / \mathrm{min}$. Incubators were supplied from the same water source, which alternated between freshwater for $8 \mathrm{~h}$ and estuarine water for $4 \mathrm{~h}$ to simulate an intertidal environment. Water temperatures, salinities, and dissolved oxygen levels were monitored periodically to ensure high-quality incubating environments.
Fertilization and fish culture. On September 15, 1993, aliquots of approximately 1,450 fertilized eggs were drawn from a genetically homogenous mixture of wild pink salmon eggs taken from an intertidally spawning stock and loaded into the incubators. The mixture was homogenized by combining the eggs from 100 females in a common container, next the mixture was divided into 100 aliquots and each aliquot was fertilized with $1.0 \mathrm{ml}$ of milt from a different male, and then the fertilized eggs were recombined in a common container and gently mixed. Immediately afterward, 200-ml aliquots of eggs were seeded into incubators in random order. After the embryos completed eyeing, all the eggs were siphoned from the incubators and counted; survivors were returned to original incubators. Eyeing is the developmental stage where eye pigment is visible through the chorion, and eggs are no longer sensitive to handling. Incubators remained covered throughout the incubation period except for a 2 -week period when hatching was evident. During that period, alevins were stimulated to burrow into the gravel by exposing them to fluorescent lights for periods consistent with the ambient photoperiod.

Most of the biological responses were measured when fry emerged from the gravel between March 15 and May 14, 1994. Fry emerged volitionally, and their yolk weights averaged $1.0 \%$ of total wet weight. For each incubator, biological observations included number of eggs loaded, number of mortalities between fertilization and eyeing, number of mortalities between eyeing and emergence, frequency of visible lesions, and size at emergence. Mortality to eyeing was measured as the ratio of dead embryos after eyeing to eggs loaded into the incubator, and mortality from eyeing to emergence was measured as the proportion of eggs alive at eyeing that failed to emerge. Emerging fry with visible lesions were categorized on the basis of the most severe lesion after visually inspecting both sides of each fish within $24 \mathrm{~h}$ of emerging. Categories included opercular hypoplasia, ascites, spinal deformities, caudal fin deformities, ophthalmic dysplasia, conjoined twinning, subcutaneous petechiae, and miscellaneous.

Hydrocarbon sampling. Concentrations of hydrocarbons on gravel, in incubator effluent, and in tissues were measured in composited samples following Marty et al. [6]. Composite gravel and water samples were collected from each dose the day before loading the incubators with fertilized eggs to determine oil doses. Subsequently, composite gravel, effluent, and fish tissue samples were collected at eyeing, hatching, and immediately after emergence. Samples were stored at $-20^{\circ} \mathrm{C}$ until they were analyzed for 44 PAHs and 23 alkanes. PAHs included un- and alkyl-substituted homologs containing from two to five rings and dibenzothiophene homologs.

Analysis of hydrocarbon samples by gas chromatographymass spectrometry (MS) was performed at the National Marine Fisheries Service, Auke Bay Laboratory; see Short et al. [8] for details. Polynuclear aromatic hydrocarbons were extracted with dichloromethane and purified by alumina/silica gel column chromatography followed by size exclusion high-performance liquid chromatography. Purified PAHs were measured by MS operated in the selected ion monitoring mode, and concentrations of PAHs in the dichloromethane extracts were determined by the internal standard method based on a suite of deuterated PAHs. Experimentally determined method detection limits (MDLs) depended on sample weights and generally were $1 \mathrm{ppb}$ for tissue or gravel and 1 to 8 pptr (nanograms per liter) for water. Concentrations below MDL were treated as 0 . All concentrations above MDL are reported on a 


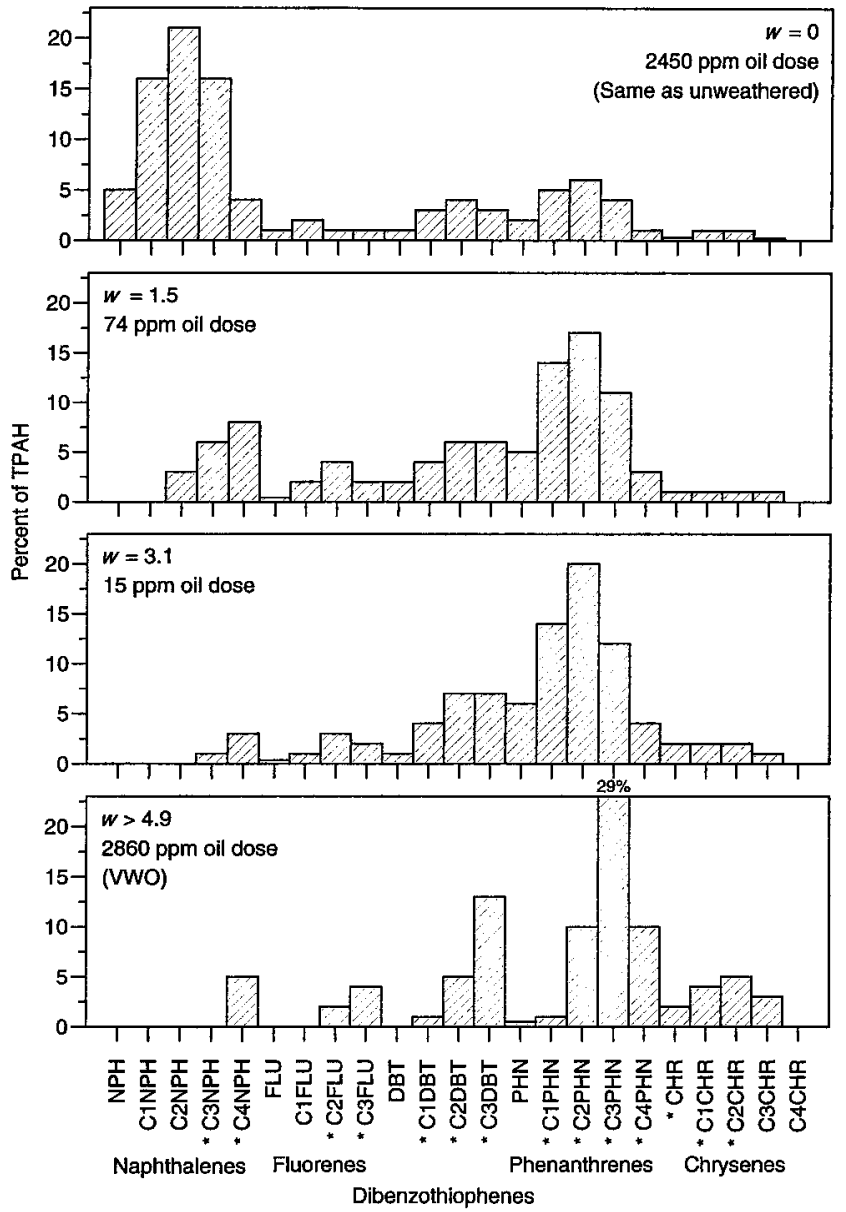

Fig. 1. As oil weathers, relative concentrations of polynuclear aromatic hydrocarbons (PAHs) with greatest surface areas increase. Values for $w$ in each panel indicate weathering state of oil in selected doses $4 \mathrm{~d}$ after contaminating gravel and immediately before loading fertilized eggs. Relative concentrations of each PAH are expressed as percentage of summed concentrations of all PAH observed in each dose (total PAH). Values for $w$ were obtained from Equation 1 (see text) using initial concentrations of 14 PAHS identified with (*) as determined by gas chromatography and mass spectrometry. Absence of C3-naphthalene in the very weathered oil (VWO) indicated it was too weathered to calculate an initial value for $w$; however, Short and Heintz [9] reported $w=4.9$ for this same dose 4 months before this experiment began.

dry weight basis for gravels and tissues. Ratios of wet and dry weights were measured by dehydrating $1 \mathrm{~g}$ of a wet sample for $24 \mathrm{~h}$ at $60^{\circ} \mathrm{C}$ and weighing the remaining mass. The accuracy of the hydrocarbon analyses was about $\pm 15 \%$, based on comparison with National Institute for Standards and Technology values, and precision, expressed as coefficient of variation, was usually less than about 20\%, depending on PAH. Total weight of PAH (TPAH) was calculated by summing the concentrations of each of the PAHs above MDL. Relative concentrations of PAHs were calculated as the ratio of the hydrocarbon concentration to the TPAH concentration.

Oil doses were determined gravimetrically following the methods of Marty et al. [6] after the first hydrocarbon samples were collected and analyzed. The oil doses were determined to be 0 (control), 15, 29, 74, 281, 717, and 2,450 $\pm 373 \mathrm{ppm}$ (mean concentration $\pm 1 \mathrm{SE}$ ).

To quantify the initial composition of the PAHs in each oil dose, the initial concentrations of 14 PAHs (Fig. 1) were fit to the following weathering model (Eq. 1). The model contains a weathering parameter, $w$, which identifies the weathering state of the oil and indexes the relative concentrations of the selected PAHs [9]:

$$
\operatorname{Ln}\left(\frac{\left[P_{i j}\right]_{0}}{\left[P_{i j}\right]}\right)=k_{j} w_{i}
$$

Here $\left[P_{i j}\right]$ is the concentration of the $j$ th $\mathrm{PAH}$ in the $i$ th sample, $\left[P_{i j}\right]_{0}$ is its concentration in unweathered oil, $k_{j}$ is a known first-order loss-rate constant for the $j$ th $\mathrm{PAH}$, and $w_{i}$ is the weathering state in the $i$ th sample. See Short and Heintz [9] for details on the theory, computations, and loss-rate constants. The magnitude of the loss-rate constants depends on the surface area of the $\mathrm{PAH}$, and these constants are greatest for the most abundant PAHs. Values of $w$ equal to 0 represent crude oil with the same composition as the oil sprayed on the gravel, and larger values indicate increasing relative proportions of the those PAHs with the greatest surface area (Fig. 1). Consequently, PAHs in water contaminated by oil with a $w$ equal to 0 will mostly be napthalenes, whereas alkyl-substituted phenanthrenes and chrysenes will characterize the PAHs in water contaminated by oil with much large values of $w$.

Statistical analysis. A one-way analysis of variance was used to examine the effects of different aqueous-TPAH concentrations on mortality rates and frequency of lesions. Dunnett's multiple pairwise comparisons with an overall $\alpha=0.05$ was used to compare mean response for each treatment to the mean response for the control incubators. For all analyses, the assumptions of homogeneity of variance and normality were examined prior to testing, and data were transformed as required to meet the assumptions. Note that the PAH composition may differ among the exposure levels because the weathering rates of the doses depends on the thickness of the oil coating the gravel [9]. However, quantifying the weathering state of each dose allowed us to unambiguously contrast the effects of similar exposure levels that differed in composition. A detailed evaluation of the influence of PAH composition on PAH uptake kinetics is described.

\section{Indirect-exposure experiment}

We incubated pink salmon eggs in the effluent of gravel contaminated with the $0,74-$, or 717 -ppm oil doses. The control and oiled gravels used in the indirect-exposure experiment were replicated in four incubators, each filled with the same gravels used for respective oil doses of the direct-exposure experiment. Eggs were exposed using the same exposure apparatus as in the direct-exposure experiment, but separated from the gravel by a perforated aluminum plate. PAH uptake in tissues was determined by measuring PAHs in composite samples of tissues collected from each of the doses at eyeing. The experiment was terminated after eyeing; otherwise, all other procedures were identical to the direct-exposure experiment. A two-way ANOVA was used to test the effects of proximity to gravel, oil dose, and their interaction. As in the direct-exposure experiment all assumptions of normality and homogeneity of variances were evaluated prior to testing.

\section{Weathered-oil experiment}

We incubated pink salmon eggs in gravel contaminated with $2,860 \mathrm{ppm}$ of oil for this experiment, using oil that had weathered on gravel for 1 year. This dose was prepared in 1992 the same way as in the direct-exposure experiment, but following preparation it was washed continuously with water for 9 months and then held outdoors in an uncovered container for 
an additional 3 months. We refer to the oil used for this dose as "very weathered oil" (VWO), and the reported oil dose $(2,860 \mathrm{ppm})$ is the concentration of oil remaining on the gravel after the oil had weathered for 1 year. The exposure apparatus, fertilization, fish culture, hydrocarbon sampling procedures, and analysis of biological responses were identical to the direct-exposure experiment, and the same control incubators were used for both experiments.

\section{Oil weathering and tissue-total weight of polynuclear aromatic hydrocarbon uptake rates}

We examined how PAH composition influences toxicity by estimating the maximum tissue-TPAH concentration and time required to reach the maximum for each of the oil doses using a first-order (FO) loss-rate (LR) kinetic model. The weathering model (Eq. 1) indicated the composition and concentration of the oil on the gravel would change as the most abundant and labile PAHs were leached to the surrounding water [9]. This meant aqueous-TPAH concentrations would be greatest when the fertilized eggs were initially loaded into the incubators, and the magnitudes of these peak concentrations would depend on the initial oil doses and weathering states. We assumed that tissue-TPAH concentrations would initially rise to a maximum as eggs took up PAHs and then decrease as aqueous-TPAH concentrations declined. Thus, the timing and magnitude of the tissue-TPAH peak concentrations would depend on the availability of PAHs as dictated by the initial composition $(w)$ and concentrations of the oil. We evaluated these assumptions by relating the peak tissue-TPAH concentration to the initial oil dose and the time required to reach the peak to the initial composition of the oil.

The model we used to express the TPAH concentration changes in water and in tissues was based on the FO kinetic model presented by Mancini [10]

$$
\frac{d C_{N}}{d t}=k_{u} C_{w}-k_{r} C_{N}
$$

where $C_{N}=$ tissue-TPAH concentration, $C_{W}=$ aqueous-TPAH concentration, $k_{u}=$ TPAH uptake rate, and $k_{r}=$ TPAH depuration rate.

Concentrations of PAHs in water decreased according to FOLR kinetics as the oil on the gravel weathered [9]. Because the most abundant PAHs in oil were also those lost most quickly [9], we assumed the concentration of TPAH in water also declined as an approximate exponential from its initial concentration, $C_{W_{0}}$, at a rate determined by a FOLR constant $k$ so that

$$
C_{W}=C_{W_{0}} e^{-k t}
$$

We substituted Equation 3 for $C_{W}$ in Equation 2 to obtain

$$
\frac{d C_{N}}{d t}=k_{u} C_{W_{0}} e^{-k t}-k_{r} C_{N}
$$

which had the following solution:

$$
C_{N}(t)=\frac{k_{u} C_{W_{0}}}{k_{r}-k}\left[e^{-k t}-e^{-k r t}\right]
$$

We determined the time of peak tissue concentration by differentiating Equation 5 with respect to time and equating the result with zero, which gave

$$
t_{\max }=\frac{\ln k-\ln k_{r}}{k-k_{r}}
$$

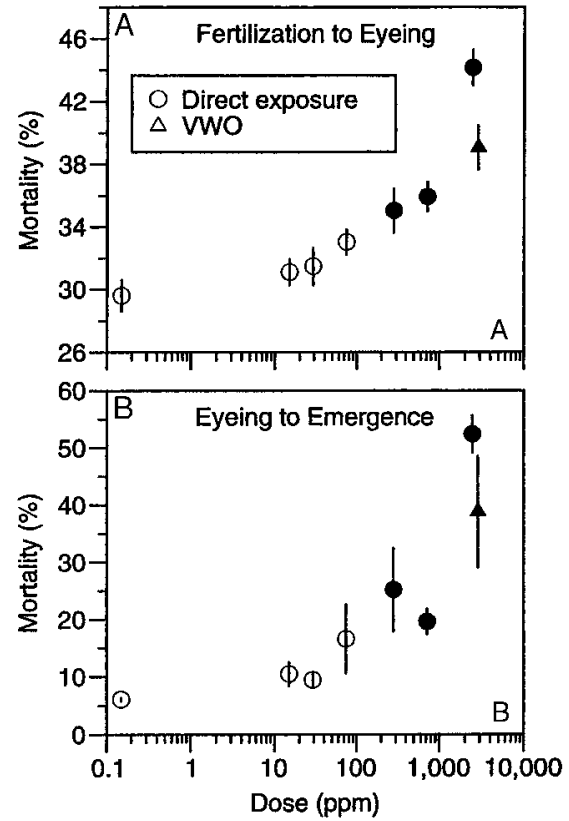

Fig. 2. Mean mortality rates $\pm 1 \mathrm{SE}$ increased for pink salmon exposed to oiled gravel during incubation in the direct-exposure and weathered-oil experiments. Mortality rate expressed as percentage dying between fertilization and eyeing (A). Mortality between eyeing and emergence (B). Filled symbols reflect rates significantly greater than that in control incubators.

The value for $t_{\max }$ from Equation 6 was substituted for time in Equation 5 to determine the peak tissue concentration $C_{N}$ at $t_{\text {max }}$. Note that when $k=k_{r}$ the time of peak concentration will equal $(k)^{-1}$, and $C_{N}\left(t_{\max }\right)$ is $\left(k_{u} C_{W_{0}}\right) /(k e)$, where $e$ is the base of natural logarithms.

We estimated $k$ as the difference in the natural logarithms of the ТРАН concentrations in water between fertilization and hatching divided by the number of elapsed days because most PAH concentrations were above MDL during that period. Similarly, we calculated $k_{r}$ as the difference in the natural logarithms of the TPAH concentrations in tissues between hatching and emergence and dividing by the number of elapsed days because low PAH concentrations in water indicated negligible uptake during this period. Finally, we estimated $k_{u}$ from Equation 5, using observations of $C_{W_{0}}$ and $C_{N}$ derived from our hydrocarbon sampling. Values of $C_{N}$ at $t_{\max }$, obtained from Equation 5, were regressed on initial oil doses to examine the relation between dose and the magnitude of peak tissue-TPAH concentration. Similarly, we regressed $t_{\max }$ on $w$ for each dose to determine how composition influences the time to reach peak tissue-TPAH concentrations.

\section{RESULTS}

\section{Direct-exposure experiment}

Lethal effects. Average mortality between fertilization and eyeing increased with dose $(p<0.001)$ from $29.6 \pm 1.0 \%$ to $44.2 \pm 1.2 \%$ for the control and highest dose, respectively (Fig. 2A). The lowest oil dose where embryo mortality was significantly greater than the controls was $281 \mathrm{ppm}$ with a mean mortality of $35.0 \pm 1.5 \%$. This oil dose had an initial aqueous-TPAH concentration of $18 \mathrm{ppb}$.

Average mortality between eyeing and emergence also increased significantly with oil dose $(p<0.001)$, ranging from $6.1 \pm 0.5 \%$ to $52.4 \pm 3.4 \%$ for the control and highest oil 
doses, respectively (Fig. 2B). The low mortality observed in the control incubators between eyeing and emergence demonstrates that under uncontaminated conditions most natural mortality occurs prior to eyeing. The lowest oil dose where embryo mortality was significantly greater than the controls was also $281 \mathrm{ppm}$ with a mean rate of $25.2 \pm 7.4 \%$. AqueousTPAH concentration did not exceed $0.5 \mathrm{ppb}$ between eyeing and emergence for this oil dose.

Sublethal effects. Direct exposure of embryos to oiled gravel during incubation increased the frequency of spinal deformities significantly $(p<0.001)$ from $0.3 \pm 0.1 \%$ for controlexposed embryos to $1.3 \pm 0.2 \%$ for the most exposed embryos. The frequencies of opercular hypoplasia increased with oil dose, but not significantly $(p=0.18)$. The significance of ascites and of other miscellaneous lesions could not be evaluated by ANOVA because variances were not homogeneous among the oil doses; however, mean frequencies of ascites increased from $0.05 \% \pm 0.03 \%$ for the controls to $1.5 \% \pm$ $0.3 \%$ for the highest oil dose, and the frequency of other miscellaneous lesions was largest for the highest oil dose. The variances associated with the mean frequencies of ascites increased significantly with oil dose $(p<0.001)$, with the highest oil dose having the greatest variance. The frequencies of conjoined twinning and ophthalmic dysplasia decreased significantly with increasing oil dose $(p<0.002)$. Conjoined twinning decreased from $0.07 \pm 0.02 \%$ in controls to nil in the two highest oil doses, and ophthalmic dysplasia decreased from $0.7 \pm 0.1 \%$ for controls to $0.02 \pm 0.07 \%$ for embryos in the highest exposure. Frequencies of the two remaining lesions examined, caudal deformities and petechial hemorrhaging, did not change significantly $(p>0.073)$ with increasing oil dose.

Polynuclear aromatic hydrocarbon accumulation and exposure levels. We observed the highest tissue-TPAH concentrations in samples of embryos collected at eyeing, $35 \mathrm{~d}$ after fertilization. Tissue-TPAH concentrations increased from 0.2 $\mathrm{ppm}$ in embryos exposed to the lowest oil dose to $45 \mathrm{ppm}$ for those in the highest oil dose (Fig. 3) compared with $0.09 \mathrm{ppm}$ for the control oil dose. Measured tissue-TPAH concentrations declined continuously to less than 0.2 ppm (Fig. 3) during the following $162 \mathrm{~d}$.

The initial concentrations of aqueous-TPAH increased linearly with oil dose $\left(p=0.002, r^{2}=0.867\right)$, ranging from 1.3 $\mathrm{ppb}$ for the lowest oil dose to $48 \mathrm{ppb}$ for the highest oil dose (Table 1) compared with $0.8 \mathrm{ppb}$ for the control dose. After $35 \mathrm{~d}$, the aqueous-TPAH concentration for all oil doses declined to less than $3 \%$ of the initial concentrations. By $191 \mathrm{~d}$, aqueous-TPAH concentrations were detectable only in the highest oil dose, which contained $0.13 \mathrm{ppb}$.

The initial concentrations of gravel-TPAH also increased linearly with oil dose, ranging from below MDL for control gravel to $33 \mathrm{ppm}$ for the highest oil dose (Table 1). After 191 days, the gravel-TPAH concentrations of all doses declined to less than $10 \%$ of their initial concentrations.

\section{Indirect-exposure experiment}

Embryo mortality and PAH uptake of embryos exposed only to dissolved PAHs were similar to results from embryos reared in direct contact with oiled gravel. The mean mortalities for the unexposed eggs were $29.8 \pm 0.7 \%$, compared to 32.3 $\pm 0.9 \%$ and $35.3 \pm 0.7 \%$ for the 74 and $717 \mathrm{ppm}$ oil doses, respectively, of the indirect exposure experiment. Mortalities for corresponding oil doses of the direct- and indirect-exposure

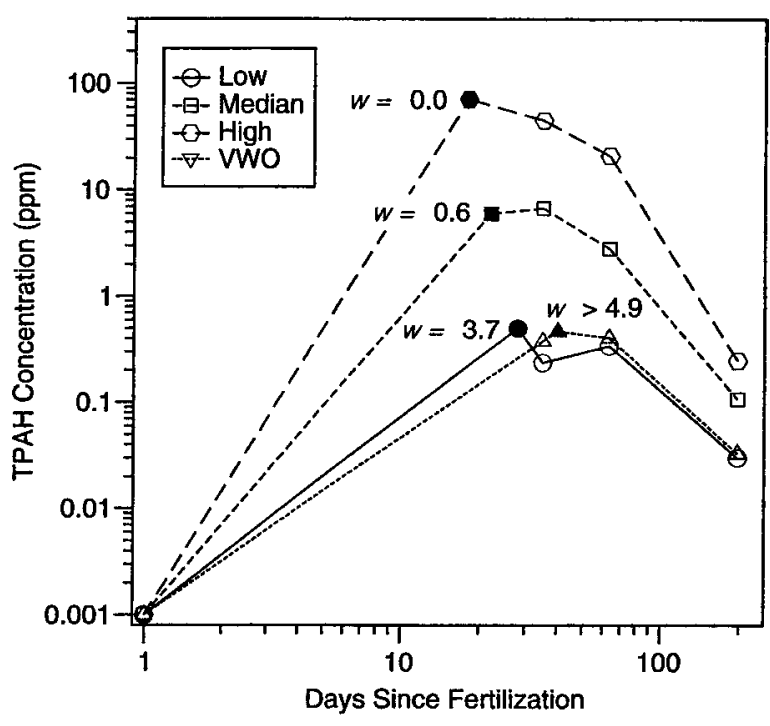

Fig. 3. Changes in tissue concentrations of total polynuclear aromatic hydrocarbon (TPAH) with time for pink salmon incubated in oil with different initial weathering states $(w)$. Lines depict uptake for highest, median, and lowest doses used in direct-exposure experiment and very weathered oil (VWO) used in weathered-oil experiment. Initial weathering states $(w)$ are adjacent to each line. Open symbols depict values obtained by gas chromatography and mass spectrometry; filled symbols depict estimates of maximum tissue-TPAH concentration, $C_{N}$ $t_{\text {max }}$, derived from Equation 5 (see text).

experiments were not significantly different $(p=0.195)$, and the absence of an interaction between oil dose and proximity ( $p=0.417)$ indicates that oil dose alone determined mortality. Mean mortality increased significantly with oil dose for both the direct- and the indirect-exposure experiments $(p=0.001)$.

Tissue-TPAH concentrations and composition in embryos exposed to corresponding doses of the direct- and indirectexposure experiments were also nearly identical (Table 2 and Fig. 4). For example, tissue-TPAH concentrations in eyed eggs exposed directly to the 717-ppm oil dose were 15 ppm compared to $13 \mathrm{ppm}$ in embryos exposed indirectly to the same oil dose. Tissue-TPAH concentrations declined similarly

Table 1. Exposure levels for pink salmon embryos in the direct exposure and weathered-oil experiments ${ }^{\mathrm{a}}$

\begin{tabular}{lccc}
\hline Oil dose & $\begin{array}{c}\text { Initial } \\
\text { weathering } \\
\text { state }(w)\end{array}$ & $\begin{array}{c}\text { Initial } \\
\text { gravel-TPAH } \\
\text { concn. } \\
(\mathrm{ppm})\end{array}$ & $\begin{array}{c}\text { Initial } \\
\text { aqueous-TPAH } \\
\text { concn. } \\
(\mathrm{ppb})\end{array}$ \\
\hline Control & N/A & 0.001 & 0.8 \\
15 & 3.7 & 0.2 & 1.3 \\
29 & 2.5 & 0.4 & 3.6 \\
74 & 1.5 & 1.0 & 7.8 \\
281 & 0.6 & 3.8 & 18.0 \\
717 & 0.3 & 9.6 & 31.0 \\
2450 & 0.0 & 32.7 & 48.0 \\
2860 (VWO) & $>4.9$ & 4.6 & 1.0 \\
\hline
\end{tabular}

a Oil doses represent the initial concentration of whole oil on gravel. Values for $w$ indicate weathering state of the oil (Eq. 1) $4 \mathrm{~d}$ after contaminating the gravel and immediately before loading fertilized eggs. Gravel-total polynuclear aromatic hydrocarbon (TPAH) and aqueous-TPAH concentrations were determined by gas chromatography and mass-spectrometry. The oil dose listed for the "very weathered oil" (VWO) used in the weathered-oil experiment reflects the concentration of whole oil on the gravel after it had weathered for approximately 1 year. 
Table 2. Comparison of total polynuclear aromatic hydrocarbon concentrations (TPAH) in pink salmon embryos exposed for $35 \mathrm{~d}^{\mathrm{a}}$

\begin{tabular}{cccc}
\hline & \multicolumn{2}{c}{$\begin{array}{c}\text { Tissue-TPAH } \\
\text { Initial } \\
\text { concn. }\end{array}$} & \multicolumn{2}{c}{$\begin{array}{c}\text { aqpm) } \\
\text { Oil dose } \\
\text { (ppm whole oil) }\end{array}$} & $\begin{array}{c}\text { concn. } \\
\text { (ppb) }\end{array}$ & $\begin{array}{c}\text { Direct } \\
\text { exposure }\end{array}$ & $\begin{array}{c}\text { Indirect } \\
\text { exposure }\end{array}$ \\
\hline Control & 0.8 & 0.1 & 0.08 \\
74 & 7.8 & 1.8 & 1.9 \\
717 & 31.0 & 15.0 & 13.0 \\
\hline
\end{tabular}

a Embryos incubated in either oiled gravel (direct exposure) or effluent from incubators containing oiled gravel (indirect exposure). Oil dose refers to the initial concentration of whole oil on gravel. AqueousTPAH concentrations represent exposure levels on the day before fertilized eggs were loaded into the incubators. Tissue-TPAH and aqueous-TPAH concentrations were determined by gas chromatography and mass spectrometry.

through emergence in directly and indirectly exposed embryos. Furthermore, the nearly identical tissue-PAH compositions for corresponding doses (Fig. 4) and the absence of phytane in these samples indicate that tissue-PAHs were dissolved in embryo lipids rather than in particles of oil adhering to eggs.

\section{Weathered-oil experiment}

Lethal effects. Embryo mortality was more protracted during exposure to the VWO dose compared with mortalities associated with the control dose. Mortality from fertilization to eyeing was $39.1 \pm 1.5 \%$ for the VWO dose compared with $29.6 \pm 1.0 \%$ for the control dose. The elevated mortalities for embryos exposed to VWO persisted between eyeing and emergence averaging $38.8 \pm 9.9 \%$, and mortality among control embryos decreased to an average $6.1 \pm 0.5 \%$. Mortalities during corresponding exposure periods were significantly higher for the VWO dose than for the control dose $(p<0.001)$.

Sublethal effects. Exposure of embryos to VWO during incubation significantly increased the frequency of opercular hypoplasia ( $p=0.026$ ) from $3.4 \pm 0.2 \%$ in controls to 13.0 $\pm 3.8 \%$ in exposed embryos. The frequencies of ascites and of other miscellaneous lesions for exposed embryos were 0.6 \pm 0.3 and $1.0 \pm 0.4 \%$, respectively, and these were comparable with corresponding frequencies observed from the two highest oil doses of the direct-exposure experiment, but they were not significantly greater than the controls $(p>0.10)$. The frequencies of spinal deformities, petechial hemorrhaging, caudal deformities, and ophthalmic dysplasia were not significantly different from control exposures $(p>0.12)$, but average frequencies were greatest among VWO-exposed embryos for all four categories. Conjoined twinning was not observed among embryos exposed to VWO, consistent with results observed for the higher oil doses of the direct-exposure experiment.

Polynuclear aromatic hydrocarbon accumulation and exposure. Embryos exposed to VWO accumulated PAHs longer than those exposed to the less-weathered oil used in the directexposure experiment. During the weathering experiment, the highest tissue-TPAH concentrations were $0.4 \mathrm{ppm}$ in samples collected at hatching, $63 \mathrm{~d}$ after fertilization (Fig. 3). This is $28 \mathrm{~d}$ later than the time when the highest tissue-TPAH concentrations were observed during the direct-exposure experiment.

The aqueous-TPAH concentration associated with the VWO dose declined from $1.0 \mathrm{ppb}$ initially to 0.2 to $0.3 \mathrm{ppb}$ at hatching and emergence. In contrast to the oil used for the direct-exposure experiment, the gravel-TPAH concentration of the VWO changed little during the exposure period, declining from $4.6 \mathrm{ppm}$ gravel initially to $3.6 \mathrm{ppm}$ at emergence. The low rate of loss was expected considering the weathering of the oil on the gravel during the previous year.

\section{Oil weathering and tissue-total weight of polynuclear aromatic hydrocarbon uptake rates}

Weathering began immediately after the gravel was oiled, leading to differences in the PAH composition of the oil doses at the time the fertilized eggs were loaded into the incubators (Fig. 1). Oil on gravel contaminated with the lowest oil doses weathered fastest. Four days after oil was applied to the gravel used for the direct-exposure experiment, estimates of $w$ increased from 0 for the highest oil dose to 3.7 for the lowest oil dose (Table 1). The value for the highest dose indicated it did not weather appreciably after it was loaded in the incubator

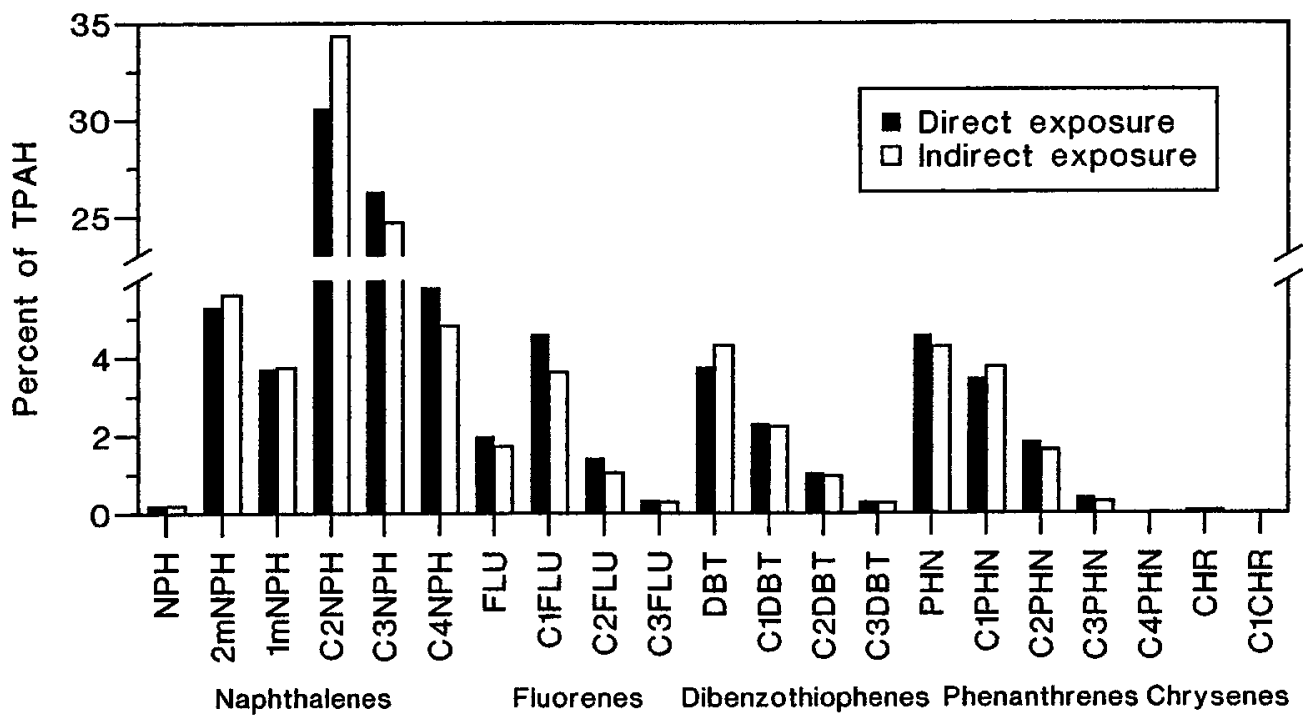

Fig. 4. Comparison of relative concentrations of specific polynuclear aromatic hydrocarbons (PAHs) in eyed pink salmon embryos that incubated in either oiled gravel (direct exposure) contaminated with $717 \mathrm{ppm}$ of oil or effluent from incubators containing the same gravel (indirect exposure). Homologs of PAHs not depicted had concentrations below method detection limits for both samples. 
and was therefore consistent in composition with the stranded EVO described in [7]. The VWO was too weathered to estimate $w$ because concentrations of C3-naphthalenes, the most labile of the 14 PAHs considered in estimates of $w$, were below MDL [9]. However, Short and Heintz [9] reported $w=4.9$ for samples of this gravel collected in March 1993.

The maximum tissue-TPAH concentration, $C_{N}\left(t_{\max }\right)$, of exposed embryos increased with oil dose but decreased with weathering. In the direct-exposure experiment, $C_{N}\left(t_{\max }\right)$ (calculated by Eq. 5, see Methods) increased significantly with oil dose from a tissue-TPAH concentration of $0.5 \mathrm{ppm}$ tissue for the lowest oil dose to $71 \mathrm{ppm}$ for the highest (Fig. 3; $p<$ $\left.0.001 ; r^{2}=0.994\right)$. However, $w$ decreased with the increasing oil doses of this experiment (Table 1). Thus, the highest oil dose in the direct exposure experiment began with the leastweathered oil and therefore contained the highest proportion of the most labile PAH. Consequently, the high abundances of labile PAH initially present led to increased maximum tissue-TPAH concentrations of embryos exposed to this highest oil dose. When exposed to oil doses of comparable magnitude but different $w$, the maximum tissue-TPAH concentration of embryos decreased with increasing $w . C_{N}\left(t_{\max }\right)$ for embryos exposed to 2,450-ppm oil dose $(w=0)$ in the direct-exposure experiment was $71 \mathrm{ppm}$ compared to $0.47 \mathrm{ppm}$ for embryos exposed to the VWO oil dose $(w>4.9)$, which was $2860 \mathrm{ppm}$.

The time required to achieve maximum tissue-TPAH concentration increased with weathering. Tissue-TPAH concentrations of exposed embryos peaked between 18 and $40 \mathrm{~d}$ after fertilization (Fig. 3). The relationship between $w$ and $t_{\max }$, the time to maximum concentration, was inversely linear $(p=$ $\left.0.003 ; r^{2}=0.910\right)$.

The extent of weathering at initial exposure strongly affected the composition of PAH accumulated by exposed embryos. The oil used for the highest oil dose of the direct exposure experiment was the least-weathered initially $(w=0)$, and most of the PAHs accumulated by embryos exposed to this oil dose were naphthalenes at $77 \%$ of the tissue-TPAH at eyeing, with chrysenes accounting for less than $0.1 \%$ of the tissue-TPAH (Fig. 5). The oil used for the lowest oil dose of the direct-exposure experiment was more weathered initially $(w=3.7)$, and the proportion of tissue-TPAH that was naphthalenes declined to $45 \%$, whereas the chrysene proportion increased to $1.5 \%$ (Fig. 5). Proportions of tissue-TPAH accumulated by embryos exposed to VWO $(w>4.9)$ were even lower for naphthalenes (32\%) and higher for chrysenes $(3.1 \%)$ (Fig. 5). The compositions of accumulated tissue-TPAH were consistently similar to the corresponding aqueous-TPAH compositions, and these were in turn consistent with the pattern of PAHs lost from the oil on the gravel. Thus, comparison of tissue-TPAH uptake rates demonstrates that the larger PAHs that predominate in more-weathered oil require more time to reach maximum tissue concentrations, attain lower concentration maxima, and persist in tissues longer compared with the smaller PAH that predominate in less-weathered oil.

\section{DISCUSSION}

The exposure conditions in our experiments that caused mortality to pink salmon embryos are consistent with environmental conditions in PWS after the EVO spill. Our experiments demonstrate that aqueous-TPAH concentrations as low as $1 \mathrm{ppb}$ derived from weathered EVO can kill pink salmon embryos located downstream from oil sources. These results corroborate the conclusions of Bue et al. [1]. The increased
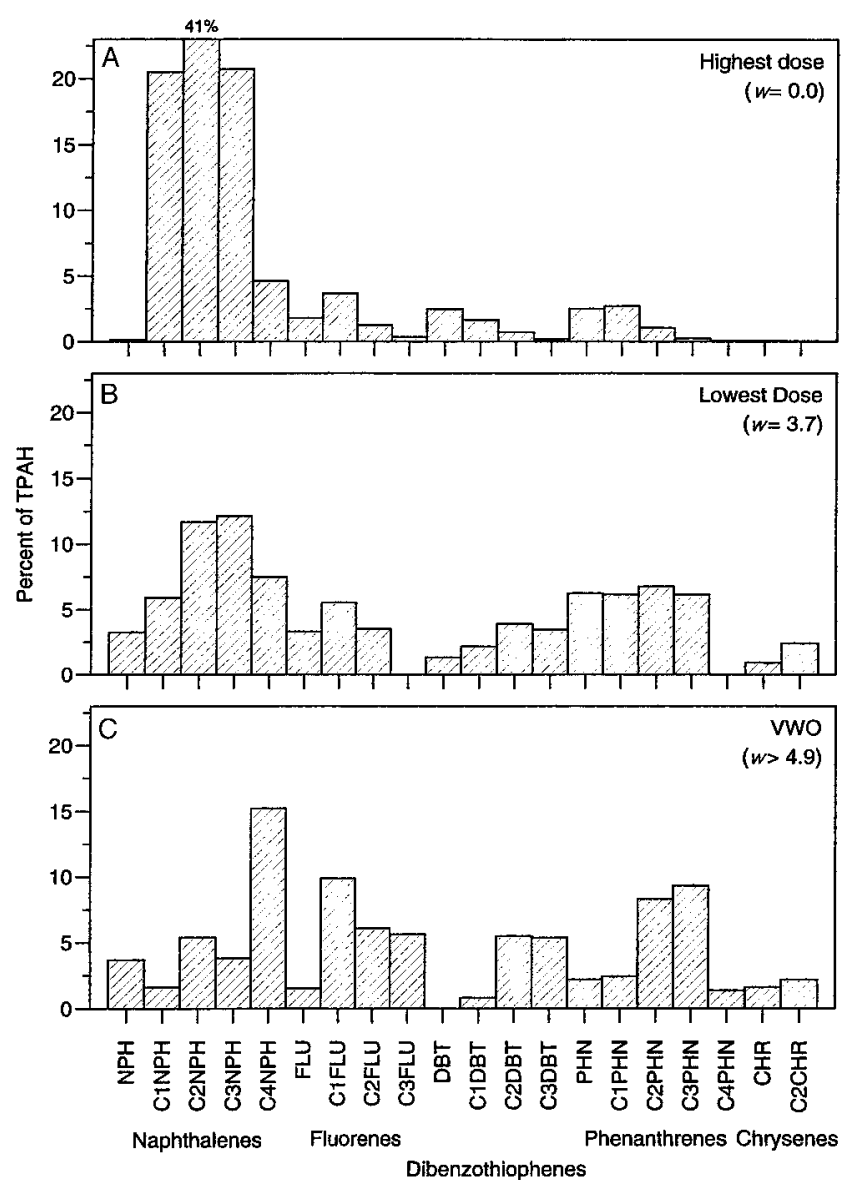

Fig. 5. Comparison of composition of polynuclear aromatic hydrocarbon (PAH) in tissues of eyed pink salmon eggs exposed to oil with different amounts of weathering. Composition in embryos exposed to highest dose in direct-exposure experiment (A). Lowest dose for that experiment (B). Very weathered oil (VWO) used in weathered-oil experiment $(\mathbf{C})$. Values for $w$ identify initial weathering state of each dose (see text). Homologs of PAH not depicted had concentrations below MDL for all three samples.

embryo mortality reported by Bue et al. [1] for streams on oiled beaches in PWS may have resulted from exposure to interstitial water contaminated by contact with oil stranded upstream from pink salmon redds.

Tidal cycling in PWS may result in an alongshore flow of contaminated interstitial seawater toward stream channels. Tidal excursions in PWS range over 5.6 vertical $\mathrm{m}$. As tides rise, increased hydrodynamic pressure forces interstitial seawater upward through beach gravel where it can contact stranded oil (Fig. 6A). As tides ebb, the contaminated interstitial seawater flows in the direction of minimum hydrodynamic potential, which may include depressions of stream channels (Fig. 6B), where less dense freshwater may be displaced upward. This hysteresis in the flow of interstitial water driven by tidal cycling accounts for seawater intrusion into intertidal pink salmon redds in PWS [11]. Thus, PAHs from oil stranded alongside stream banks or in pools trapped by natural dams may dissolve into interstitial water, which is then transported to salmon redds dug into stream beds.

Beach gravel contaminated by EVO was often detected near, but not in, stream beds of oiled beaches in 1989. When spilled oil washed ashore, the freshwater flow of streams tended to divert the oil away from stream beds. Samples of stream bed gravels collected in 1989 from streams on oiled beaches 


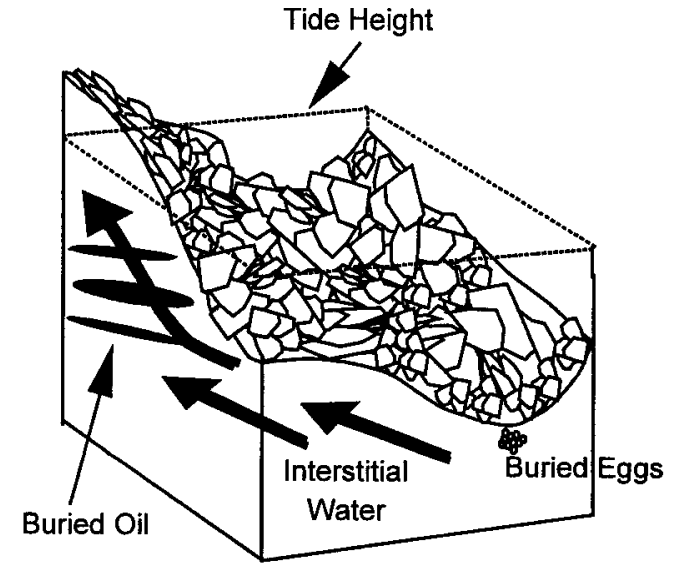

A. Rising Tide

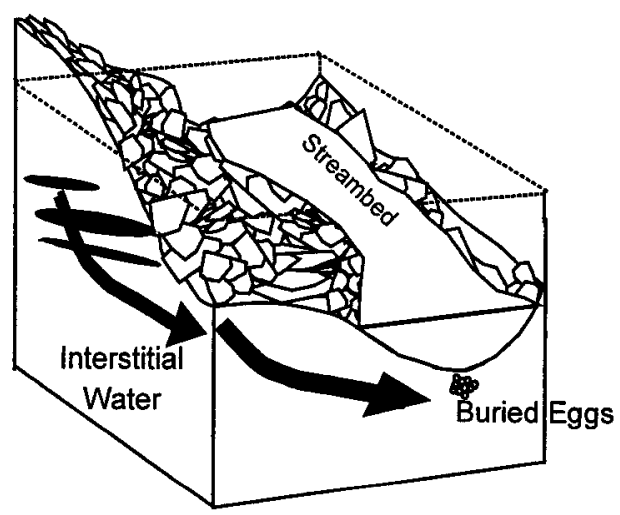

B. Falling Tide

Fig. 6. Generalized flow of interstitial water past buried pockets of stranded Exxon Valdez oil during rising $(\mathbf{A})$ and falling $(\mathbf{B})$ tides near an intertidal pink salmon spawning channel at a typical oiled beach of Prince William Sound. Net flow over tidal cycle tends to transport polynuclear aromatic hydrocarbon (PAH) leached from oil pockets toward gravel underlying spawning channels.

therefore usually contained negligible PAH burdens [3]. However, samples collected from visibly oiled beach gravel adjacent to banks of these streams contained TPAH concentrations as high as 500 ppm [4], which is much higher than the TPAH burden of the gravels we used for these experiments. Comparison of our results from the direct- and indirect-exposure experiments clearly shows that dissolved PAHs may damage or kill developing pink salmon embryos and that embryo contact with oiled substrate is not a necessary exposure condition. This conclusion is consistent with results reported by Roesijadi [12], who exposed clams (Macoma inquinata) directly to sediments oiled with Prudhoe Bay crude and suspended another group above the sediments and found their uptake rates differed by no more than one order of magnitude. It also supports the conclusion of Marty et al. [6], based on interpretation of hydrocarbon uptake, that PAHs dissolved in water determine tissue concentrations.

The composition of the EVO stranded on the beaches in PWS was identical to the compositions used this experiment. Changes in the relative concentrations of the PAHs in the oil doses used in this study formed the basis for estimating the loss-rate constants described by Short and Heintz [9] (Eq. 1). These constants were used to identify PAH sources in environmental samples collected in the EVO spill zone [9]. Thus, the range of weathering states used for this study determined the scale used for calculating the weathering states of environmental samples known to be contaminated by EVO.

The mechanism we postulate to exist for PWS can cause lethal concentrations of PAHs in pink salmon embryos even if the embryos are intermittently exposed to PAHs. Accumulation of PAHs by exposed embryos is determined by passive uptake and depuration kinetics (see Eq. 2) and is not affected by metabolism prior to hatching [13]. After hatching, the lipid compartment contracts rapidly to support further embryonic development. Thus, prior to hatching, Equation 2 predicts that tissue-PAH accumulation will occur if $C_{W}$ is any positive function of time, i.e., no matter how variable the concentration of PAH in the exposure medium [14]. In our experiment and in PWS, embryos initially contain no PAHs and are exposed to aqueous-PAH concentrations that generally decline. These initial conditions necessarily imply that tissue PAH burdens reach a maximum sometime following initial exposure. The maximum tissue-TPAH concentrations we observed in the laboratory experiments occurred prior to eyeing, which is considered the most sensitive developmental period [15]. In PWS, the period of maximum tissue-TPAH accumulation would depend on the how quickly PAHs are depleted from the sources of upstream oil and may therefore be longer if these sources are persistent.

The toxicity associated with oil introduced into PWS could persist on time scales of years if the larger PAHs caused the adverse effects we observed for embryos exposed to VWO. The persistence of phenanthrenes and chrysenes in VWO, which was washed with water for a total of 18 months, clearly demonstrates that these PAHs may persist in oil exposed to the environment for years. The relative surface area of the VWO in our experiment was substantially greater than that in oil pockets that formed in interstitial gravel of PWS beaches following the spill, so the persistence of larger PAHs in these pockets would be even longer [9]. Because the rate that all PAHs are released into the environment increases with the relative surface area of the oil [9], environmental perturbations such as storms or stream bed changes may disperse relatively unweathered oil pockets in interstitial beach gravels, and the accelerated weathering caused by the increased surface area of the oil would lead to accelerated release of PAH into the environment. Consequently, stranded pockets of relatively unweathered interstitial oil may act as toxic reservoirs that may persist for several years until dispersed by a disturbance event. Thus, long-term effects resulting directly from oil exposure are long term in the sense that the PAHs leach over time scales measured in generations. These types of long-term effects are different from effects observed in organisms long after oil exposures have ended, such as reports of reduced gamete viability among adult pink salmon when they return to natal streams on oiled beaches in PWS [2].

The adverse effects we observed for embryos exposed to VWO corroborates the persistence of embryo mortality claimed by Bue et al. [2] 4 years after the spill. Both observations indicate susceptibility of pink salmon embryos to low concentrations of the least labile PAH. The toxicity of PAHs generally increases with size [16], so the most toxic PAHs that are relatively abundant in EVO are the phenanthrenes and chrysenes. These PAHs are also the most persistent in EVO [9] and in tissues, once accumulated [16]. In our experiment with VWO, the concentrations of phenanthrenes and of chrysenes in the exposure water declined relatively little during 
the 191-d exposure period, consistent with the relatively small losses we observed for these PAHs from the oiled gravel. Thus, embryos were exposed to relatively constant aqueous concentrations of these PAHs, and Equation 2 implies that these PAHs will be accumulated and retained by exposed embryos for a larger portion of the embryonic developmental period.

Comparison of the adverse effects caused by exposure to VWO and to less-weathered oil used in the direct-exposure experiment indicates the smaller PAHs contribute relatively little to observed toxicity. The concentrations of the phenanthrenes and chrysenes and mortality rates were approximately the same in VWO and the highest doses used in the directexposure experiment throughout the exposure period. This similarity in the composition of the oils used for these exposures coupled with the similarity in their lethal effects suggests that contributions to lethality by smaller PAHs were negligible in the direct-exposure experiment.

The sublethal effects we observed among exposed embryos are characteristic of chemical teratogenesis [17]. These include altered development of bony parts such as increased frequencies of opercular hypoplasia and of spinal deformities. We also noted possible effects on circulation manifested as increased frequency of ascites and possible cytogenetic effects demonstrated by reductions in the frequency of conjoined twinning. Under normal hatchery conditions, conjoined twinning is typically seen at low frequencies [18]. Our observations of reduced frequency for this lesion suggests that some developmental abnormalities manifested under normal circumstances may interact with the oil effects to preclude survival. The increased frequency of ophthalmic dysplasia we observed among embryos exposed to the VWO, contrasted with decreased frequencies observed among embryos exposed to lessweathered oil, suggests a similar interaction of the smaller PAHs from the less-weathered oil with developmental abnormalities that lead to this lesion.

Accumulation of PAHs by embryos in our experiment depends on the efficiency of PAH transfer from oil to embryos as mediated by the kinetics of the transfer processes rather than on PAH solubilities. Our experiments show that the lipidrich embryos can effectively scavenge PAHs dissolved from the oiled gravel to toxic internal concentrations, despite the low solubilities of the larger PAHs. This is because PAHs that escape from the oil tend to be permanently removed by the flowing water, where the PAHs concentration remains so low that the rate of condensation back to the oil is negligible. However, when aqueous PAHs contact the lipid-rich embryos, the initial absence of PAHs in the embryos implies initial net $\mathrm{PAH}$ uptake. In this way, PAHs may become redistributed among available low-polarity compartments in our experiments or in the environment without ever approaching equilibrium with the intervening aqueous medium.

A consequence of PAH uptake mediated by transport kinetics is that PAHs are accumulated more rapidly by smaller embryos. The surface area per unit volume of eggs increases inversely with the radius. The absolute uptake rate of PAHs is directly proportional with the ratio of surface area to volume, so smaller eggs accumulate all PAHs more rapidly than larger eggs. For example, the smaller eggs of Pacific herring (Clupea harengus pallasii) accumulated PAHs more rapidly than did those of pink salmon when they were exposed to PAH dosing conditions comparable with those of this study [19], and exposed herring eggs had increased mortality rates at initial aqueous-TPAH concentrations as low as $0.7 \mathrm{ppb}$.
Initial aqueous-TPAH concentrations that led to increased embryo mortality in our VWO experiment were substantially lower than the current water quality standard for TPAH in Alaska. Increased mortality occurred among embryos exposed to initial aqueous-TPAH concentrations of $1.0 \mathrm{ppb}$, which is one tenth the current water quality standard for TPAH in Alaska (State of Alaska Water Quality Standard Regulations 18 AAC 70). The current water quality standard was established at $1 \%$ of the lowest dose known to cause adverse effects. On this basis, our results indicate the current water quality standard should be lowered to 10 pptr. However, this may not be practical or even appropriate.

Measurement of aqueous-TPAH concentrations near 10 pptr is below the detection limits of all but the most expensive analytical methods currently available. The expense of monitoring PAHs at these concentrations would therefore be prohibitive. Furthermore, the temporal variability of aqueousPAH concentrations is notoriously high, so obtaining representative samples is correspondingly difficult. Monitoring tissue-PAH concentrations in species of concern may be more practical because these concentrations are likely to be higher and less temporally variable than PAH concentrations of the exposure water. Alternatively, monitoring PAHs at the point of introduction to the environment may also be substantially more practical, for similar reasons.

The composition of TPAH released into the aqueous environment may be as important a factor to regulate as the concentration. Different PAHs may produce adverse effects that are approximately additive, so regulating PAHs individually and in isolation may not provide adequate protection. However, regulatory concern should focus on the larger PAHs because these are more toxic and persistent once incorporated into tissues.

The adverse effects found for embryos exposed to low partper-billion TPAH concentrations reported here and by Carls et al. [19] suggests that restoration of habitats chronically polluted with PAHs may be even more difficult than previously appreciated. The larger and more toxic PAHs will most likely persist longest at locations where PAHs are continually leached into receiving aquatic habitats. The effects of these PAHs on organisms in these habitats may be sublethal at early life stages but may lead to mortality later in life by increasing the vulnerability of these organisms to disease, parasitism, or predation. In our experiments, embryos exposed to PAHs exhibited a variety of adverse effects, and although the frequencies of these effects were often low, the cumulative impact on the exposed population may be substantial. Concentrations of aqueous-TPAH above $1 \mathrm{ppb}$ may be readily attained in surface waters of urbanized drainages, so cumulative impacts on fish populations attempting to reproduce in PAH-contaminated surface waters of these drainages may be greater than currently recognized. Reduction of PAH inputs to safe levels for restoration and maintenance of healthy, self-sustaining fish populations may therefore require much more restrictive regulation of anthropogenic PAH sources.

Acknowledgement-We thank Robert Bradshaw for signficant logistical contributions to this experiment. We also thank Brian Bue, Sam Sharr, and Jim Seeb for comments on the study design and Elisa Joel, Jennifer Weinlaeder, and Jacek Maselko for help processing fish. This work was funded by the Exxon Valdez Oil Spill Trustee Council. However, the conclusions presented by the authors are their own and do not necessarily reflect those of the Trustee Council. 


\section{REFERENCES}

1. Bue BG, Sharr S, Moffitt SD, Craig AK. 1996. Effects of the Exxon Valdez oil spill on pink salmon embryos and pre-emergent fry. Proceedings, Exxon Valdez Oil Spill Symposium, Anchorage, AK, USA, February 2-5, 1993, pp 619-627.

2. Bue BG, Sharr S, Seeb JE. 1997. Evidence of damage to pink salmon populations inhabiting Prince William Sound, Alaska, two generations after the Exxon Valdez oil spill. Trans Am Fish Soc 127:35-43.

3. Brannon EJ, Moulton LL, Gilbertson LG, Maki AW, Skalski JR. 1995. An assessment of oil spill effects on pink salmon populations following the Exxon Valdez oil spill - part 1: Early life history. In Exxon Valdez Oil Spill: Fate and Effects in Alaskan Waters. STP 1219. American Society for Testing and Materials. Philadelphia, PA, pp 548-584.

4. Heintz R, Weidmer M, Rice SD. 1995. Laboratory evidence for short and long-term damage to pink salmon incubating in oiled gravel. Proceedings, 17th Northeast Pacific Pink and Chum Salmon Workshop. Bellingham, WA, USA, March 1-3, pp 142-146.

5. Heard WR. 1991. Life history of pink salmon (Oncorhynchus gorbuscha). In Groot C, Margolis L, eds, Pacific Salmon Life Histories. University of British Columbia Press, Vancouver, BC, Canada.

6. Marty GD, Short JW, Dambach DM, Willits NH, Heintz RA, Rice SD, Stegeman JJ, Hinton DE. 1997. Ascites, premature emergence, increased gonadal cell apoptosis, and cytochrome P4501A induction in pink salmon larvae continuously exposed to oilcontaminated gravel during development. Can J Zool 75:9891007.

7. Bence BE, Burns WA. 1995. Fingerprinting hydrocarbons in the biological resources of the Exxon Valdez spill area. In Exxon Valdez Oil Spill: Fate and Effects in Alaskan Waters. STP 1219. American Society for Testing and Materials. Philadelphia, PA, pp 84-140.

8. Short JW, Jackson TJ, Larsen ML, Wade TL. 1996. Analytical methods used for the analysis of hydrocarbons in crude oil, tissues, sediments, and seawater collected for the natural resources damage assessment of the Exxon Valdez oil spill. Proceedings,
Exxon Valdez Oil Spill Symposium. Anchorage, AK, USA, February $2-5,1993$, pp 140-148.

9. Short JW, Heintz RA. 1997. Identification of Exxon Valdez Oil in Sediments and Tissues from Prince William Sound and the Northwestern Gulf of Alaska Based on PAH Weathering. Environ Sci Techol 31:2375-2384.

10. Mancini JL. 1983. A method for calculating effects, on aquatic organisms, of time varying concentrations. Water Res 17:13551363.

11. Helle JH, Williamson RS, Bailey JE. 1964. Intertidal ecology and life history of pink salmon at Olsen Creek, Prince William Sound, Alaska. Report 483. US Department of Interior, Fish and Wildlife Service, Washington, DC.

12. Roesijadi G, Anderson JW, Blaylock JW. 1978. Uptake of hydrocarbons from marine sediments contaminated with Prudhoe Bay crude oil: Influence of feeding type of test species and availability of polyclyclic aromatic hydrocarbons. J Fish Res Board Can 35:608-614.

13. Andersson T, Förlin L. 1992. Regulation of the cytochrome P450 enzyme system in fish. Aquat Toxicol 24:1-20.

14. Hickey BE, McCarty LS, Dixon DG. 1997. A residue-based toxicokinetic model for pulse-exposure toxicity in aquatic systems. Environ Toxicol Chem 14:2187-2197.

15. Piper RG, McElwain IB, Orme LE, McCraren JP, Fowler LG, Leonard JR. 1982. Fish hatchery management. U.S. Department of Interior, Fish and Wildlife Service. Washington, DC.

16. Neff JM, Anderson JW, Cox BA, Laughlin RB, Rossi SS, Tatem HE. 1976. Effects of petroleum on survival, respiration and growth of marine animals. In Proceedings, Sources, Effects and Sinks of Hydrocarbons in the Aquatic Environment, Washington, DC, USA, August 9-11, pp 516-540.

17. Weis JS, Weis P. 1989. Effects of environmental pollutants on early fish development. Aquat Sci 1:42-73.

18. Marty GD, Heintz RA, Hinton DE. 1997. Histology and teratology of pink salmon larvae near the time of emergence from gravel substrate in the laboratory. Can J Zool 75:981-988.

19. Carls MG, Rice SD, Hose JE. 1998. Sensitivity of fish embryos to weathered crude oil: Part I: Low-level exposure during incubation causes malformations, genetic damage, and mortality in larval Pacific herring (Clupea pallasi). Environ Toxicol Chem 18:481-493. 